\title{
Is Herd Immunity Against SARS-CoV-2 a Silver Lining?
}

\author{
Ramachandran Vignesh ${ }^{1,2 *}$, Esaki M. Shankar ${ }^{3 *}$, Vijayakumar Velu ${ }^{4,5 *}$ \\ and Sadras Panchatcharam Thyagarajan ${ }^{6 *}$ \\ 1 Preclinical Department, Royal College of Medicine Perak (UniKL RCMP), Universiti Kuala Lumpur, Ipoh, Malaysia, \\ 2 Infectious Diseases Laboratory, YRG Centre for AIDS Research and Education, Chennai, India, ${ }^{3}$ Infection Biology, \\ Department of Life Sciences, Central University of Tamil Nadu, Thiruvarur, India, ${ }^{4}$ Division of Microbiology and Immunology, \\ Yerkes National Primate Research Center, Emory University, Atlanta, GA, United States, ${ }^{5}$ Department of Pathology and \\ Laboratory Medicine, Emory Vaccine Center, Emory University, Atlanta, GA, United States, ${ }^{6}$ Central Research Facility, Sri \\ Ramachandra Institute of Higher Education and Research, Chennai, India
}

Keywords: herd immunity, coronavirus disease 2019, severe acute respiratory syndrome coronavirus-2, seroprevalence, vaccines

\section{OPEN ACCESS}

Edited by:

Francesca Chiodi,

Karolinska Institutet (KI), Sweden

Reviewed by:

Amit Awasthi,

Translational Health Science and

Technology Institute (THSTI), India

*Correspondence:

Sadras Panchatcharam Thyagarajan deanresearch@sriramachandra.edu.in

Vijayakumar velu

vvelu@emory.edu

Esaki M. Shankar shankarem@cutn.ac.in

Ramachandran Vignesh vignesh@unikl.edu.my

Specialty section:

This article was submitted to Viral Immunology,

a section of the journal

Frontiers in Immunology

Received: 24 July 2020 Accepted: 14 September 2020 Published: 30 September 2020

Citation:

Vignesh R, Shankar EM, Velu V and Thyagarajan SP (2020) Is Herd Immunity Against SARS-CoV-2 a Silver Lining?

Front. Immunol. 11:586781. doi: 10.3389/fimmu.2020.586781

\section{INTRODUCTION}

The emergence of a novel coronavirus severe acute respiratory syndrome coronavirus-2 (SARSCoV-2) in late 2019 and its wide global spread has led to millions of infections and substantial morbidity and mortality (1). Coronavirus disease 2019 (COVID-19) caused by SARS-CoV-2 infection can range from mild self-limiting disease to acute respiratory distress syndrome and death (2). With the WHO having reported 31,174,627 confirmed cases and 962,613 deaths globally as of 22nd September 2020, the COVID-19 pandemic seems to show almost poor indication of abating (3). While the global scientific community is racing against time to strategize combating possibilities, with several vaccine trials, drug discoveries and validations underway, we still need a practical and sustainable solution to face the ongoing threat to global public health.

The terminology "herd immunity", coined by Topley and Wilson in 1923, later formed the basis for vaccines, applications and vaccination programs, especially against certain viral infections (4). The concept of herd immunity refers to the indirect protection from infection conferred on susceptible individuals when a sufficiently large proportion of individuals immune to the infection exist in a population. Herd immunity concept is generally applicable to those infections that are transmitted directly from person to person and for those humans serving as the reservoir of infection. History has shown that a significant drop in the number of cases and even eradication is rendered by vaccines, and herd immunity is achieved against infectious diseases like small pox, polio, measles, rubella, diphtheria, pertussis and mumps (4-7). The concept of herd immunity appears to be highly critical in the context of disease elimination programs because the said eradication of an infectious agent becomes possible in spite of the absence of an effectual vaccine. Interestingly, natural herd immunity is a classical concept that has been successfully accomplished in instances like the $1918 \mathrm{H} 1 \mathrm{~N} 1$ influenza pandemic wherein no vaccine was available (8).

Going by this old school modus operandi, in the absence of a vaccine, building natural herd immunity against SARS-CoV-2 is theoretically considered feasible. However, letting an existing super infectious condition to run amok in the pretext of building up effective herd immunity might not be a smart strategy to end the pandemic. It requires judicious analyses to avoid the colossal burden it could inflict on the healthcare system and the surge in mortalities and associated complications. 
In a detailed classical analysis, Fox et al. has listed down the following four conditions for effective herd immunity to ensue (i) the infectious agent must exist and be restricted to a single host, (ii) the transmission must occur primarily through direct contact, (iii) the infection must induce a robust and life-long immunity, and (iv) the cumulative or herd immunity is amplified if the population possesses a random mixing pattern (9). Applying the aforementioned conditions to herd immunity against SARS-CoV-2, though the infectious agent has been identified and believed to be zoonotic, we are yet to place a finger on the intermediate host (10). Secondly, the transmission, of course, occurs through direct person-to-person contact (11). However, regarding the third condition, we have a paucity of data on the immune response elicited by SARS-CoV-2 in humans, till date (12) and the questions remains about the long-lasting immunity for the exposed individuals. Finally, though the entire human population is susceptible to COVID19 , the mixing of the pattern varies that is dependent on several societal factors and practices such as universal lockdown, mass quarantine, isolation, social distancing and public health preventive measures, particularly for those at risk (12).

Table 1 listed the various infectious agents and their corresponding $\mathrm{R}_{0}$ values and herd immunity thresholds. While earlier studies have estimated the basic reproductive number $\left(\mathrm{R}_{0}\right)$ of SARS-CoV-2 to be in the range of 2 to 3 , recent estimates place the $R_{0}$ at $5.7(13,15)$. This indicates the highly infective nature of the virus, meaning that on an average each infected individual can give rise to about 5.7 newer infections and subsequently spread the agent on an exponential scale. Assuming an $\mathrm{R}_{0}$ estimate of 5.7, using the mathematical formula $1-1 / R_{0}$, the herd immunity threshold for COVID-19 would be $\sim 82.5 \%$, meaning that the incidence of infection will begin to decline once the proportion of individuals with acquired immunity to SARS-CoV-2 in the population exceeds $82.5 \%$. However, it remains to be noted that the estimate of the proposed threshold is only theoretical with the assumptions of a homogenous population and presence of uniform sterilizing immunity in the recovered patients. Mathematical modeling studies have shown that disease-induced herd immunity threshold would be substantially lower than the values calculated by conventional formula due to the population heterogeneity $(16,17)$.

TABLE 1 | $R_{0}$ values and corresponding herd immunity threshold values of infectious diseases $(5,6,13,14)$.

\begin{tabular}{llcc}
\hline S. no. & Infectious diseases & $\mathbf{R}_{\mathbf{0}}$ value & Herd immunity threshold \\
\hline 1 & Small pox & $5-7$ & $80-85 \%$ \\
2 & Mumps & $4-7$ & $75-86 \%$ \\
3 & Measles & $12-18$ & $92-94 \%$ \\
4 & Diphtheria & $6-7$ & $85 \%$ \\
5 & Pertussis & $12-17$ & $92-94 \%$ \\
6 & Polio & $4-13$ & $75-92 \%$ \\
7 & Rubella & $6-7$ & $83-85 \%$ \\
8 & H1N1 (2009 Pandemic) & 1.6 & $40 \%$ \\
9 & SARS & $2-4$ & $50-75 \%$ \\
10 & SARS-CoV-2 (COVID-19) & 5.7 & $82.5 \%$
\end{tabular}

Furthermore, there are several instances of "super spreading events" reported from various countries, wherein a single patient goes on to infect far more number of people than an average patient does, based on estimated $\mathrm{R}_{0}$ value (18). Several factors such as increased viral load, asymptomatic individuals, immune suppression and extensive social interactions have been implicated in these "super-spreading events" (19). Studies point towards these "super-spreaders" as the reason for the heterogeneous propagation of SARS-CoV-2 across geographical locations and since these present with a relatively higher $\mathrm{R}_{0}$ value, they could potentially impact the dynamics of spread and lower the herd immunity threshold $(20,21)$. The whole concept of herd immunity against SARS-CoV-2 hinges on the assumption that an infection would generate sufficient, effective and protective long-lasting immunity. However, data are scarce if the acquired immunity developed by humans is sterilizing enough and whether it would stay long enough.

\section{RAYS OF HOPE}

Earlier studies on survivors of SARS-CoV-1 and MERS-CoV infections have shown that the antibodies against SARS-CoV-1 persisted for nearly two years and antibodies to MERS-CoV lasted for almost 3 years $(22,23)$. Besides, studies have also demonstrated evidence of seroconversion within 14 to 19 days of disease onset among SARS-CoV-2 patients with COVID-19 (24, 25). A study has reported the interesting finding of $\mathrm{T}$ cell reactivity to SARS-CoV-2 in about $50 \%$ of specimens collected between 2015 and 2018 before the viral emergence (26). This could reflect the circulating $\mathrm{T}$ cell memory to the seasonal coronaviruses- 229E, OC43, NL63, and HKU1. A study also suggests that SARS-CoV-2-reactive antibody responses have been detected in unexposed individuals who are IgG seropositive for OC43 and NL63 and this cross-immune reactivity mainly targets viral $1 \mathrm{AB}$ polyprotein and $\mathrm{S}$ proteins, these viral antigens have high sequence similarity with low pathogenic human coronaviruses and SARS-CoV-2 $(27,28)$. In addition, a study has also shown that these antibodies were particularly prevalent in children and adolescents (29). It is also important to note that sera from uninfected individuals exhibited variability in their reactivity, they are reactive with SARS-CoV-2 $\mathrm{S}$ and nucleoprotein but not with the S1 subunit or the receptor binding domain (RBD) of spike protein. Since many studies from different geographical locations are documenting preexisting immunity to SARS-CoV-2, it will be important to define specificities of these $\mathrm{T}$ and $\mathrm{B}$ cell immune response carefully to assess their association with COVID-19 disease severity. This preexisting cross-reactive $\mathrm{T}$ and $\mathrm{B}$ cell immunity to SARS-CoV-2 may have wide implications as this could explain differential clinical outcomes in COVID-19 patients, disease severity, vaccine development, and important in accessing herd immunity for SARS-CoV-2 viral infection/COVID-19 disease.

Studies characterizing the SARS-CoV-2-specific T cell responses suggest that there is marked activation of $\mathrm{T}$ cells in 
acute COVID-19 patients (30-32). Several studies have provided strong evidence for the importance of SARS-CoV-2 specific CTLs, and $\mathrm{T}$ helper cells in mild and moderate patients compared to severe COVID-19 disease $(27,28,31-33)$. The effector memory CD8 T cell population is decreased in the severe patients compared to the recovered patients (34-36). Similarly, the $\mathrm{T}$ cells in severe patients compared to convalescent patients express higher levels of exhaustion markers PD-1 and CD39 on the memory CD8 $\mathrm{T}$ cells with the signature pertaining to hyperimmune activation ( $\mathrm{HLADR}^{+} \mathrm{CD} 38^{+} \mathrm{CD} 8^{+}$) with lower CD8 $\mathrm{T}$ cell response. In line with $\mathrm{CD} 8 \mathrm{~T}$ cells, the effector memory CD4 T cell frequencies are also elevated in the COVID19 patients (34-36). Interestingly, the recovered patients seem to have higher levels of activated circulating $\mathrm{T}$ follicular helper (Tfh) population, indicative of recent antigen encounter and emigration from germinal center. Similar to the PD-1 levels of CD8 T cells, the PD-1 levels were increased in the CD4 T cells. As a result of the decrease in the $\mathrm{T}$ cells, non- $\mathrm{T}$ cell frequencies that includes, macrophages, monocytes, neutrophils were observed to be elevated in severe COVID-19 patients $(30,34)$. Similar to T cells the B cell subpopulations are altered in the COVID-19 disease and it has been shown that the frequency of plasmablast is highly elevated (30\% of the circulating B cells) in the COVID19 patients (34). These blood plasmablast frequencies are shown to correlate with activated circulating Tfh cells $(34,37)$. The proliferating $\mathrm{B}$ cells are markedly elevated in the COVID-19 patients with activated phenotype, suggestive of altered B cell response during COVID-19 disease. Several studies have provided strong evidence for the importance of SARS-CoV-2 specific neutralizing antibodies in association with less disease severity in COVID-19 patients $(38,39)$. SARS-CoV-2 specific antibodies are found in convalescent plasma and most recovered individuals have RBD-specific antibodies with potent antiviral activity $(40,41)$, importantly severe and critical patients are currently being treated with convalescent plasma therapy in many parts of the world $(42,43)$. Overall, these data suggest that vaccines or therapeutic strategies that induce functional anti-viral SARS-CoV-2 specific $\mathrm{T}$ and $\mathrm{B}$ cell responses are important to curtail SARS-CoV-2 infection in vivo.

\section{ENIGMA OF UNKNOWNS}

There remain many unknowns and several other research questions unanswered. The degree of protection afforded by the antibodies against SARS-CoV-2 among the infected is still ambiguous, and strong evidence-based findings are awaited to know if the host responses generated would be of strong sterilizing or weak and waning immune responses. Earlier studies on the coronavirus 229E, responsible for common cold have shown that the titers of antibodies produced were not sufficient to prevent reinfection in all the individuals studied (44). Interestingly, similar pattern exists in SARS-CoV-2 infection and where there is a rapid decay of SARS-CoV-2 of antibodies in persons with mild symptoms and recovered patients $(45,46)$. Similarly, as a recent study demonstrated the evidence of reinfection of SARS-CoV-2 by phylogenetically distinct SARS-CoV-2 re-infection, this may also suggest that the immunity generated during primary SARS-CoV-2 infection may be short lived and may not protect if reinfection happens by the second distinct virus (47). These results also suggest that SARS-CoV-2 may continue to circulate among human population despite herd immunity with natural infection or with vaccination. However, a recent study on monkeys has indicated the development of protective immunity against reexposure to SARS-CoV-2 (homologous) (48). Hence, massive longitudinal monitoring of SARS-CoV-2 seroprevalence remains the need of the hour to determine the percentage of the population already infected and if reaching a herd immunity threshold is even feasible. It also remains logical to consider the viral factors such as the possibility of mutations and emergence of new strains of a virus, which can go on to make herd immunity futile (49).

\section{POTENTIAL CONSEQUENCES AND WAY FORWARD}

Given the unavailability of a vaccine against SARS-CoV-2, it is prudent to foresee the consequences of achieving the herd immunity threshold in epidemiological and immunological viewpoints. A recent population-based sero-epidemiological study from Spain involving 61075 participants has revealed $\sim 5 \%$ seroprevalence of SARS-CoV-2, thereby highlighting that the majority of the Spanish population remains seronegative (50). Figure 1 represents this scenario of a population with only $5 \%$ seroprevalence of SARS-CoV-2 antibodies and the importance of achieving herd immunity threshold. Similarly, seroprevalence among the community in Los Angeles County has been reported as $4.34 \%$, about $3.3 \%$ in Japan, and $2.73 \%$ in Hong Kong (51-53). Based on a serological survey conducted by the Indian Council for Medical Research (ICMR) in May - June, 2020 across 83 districts in India involving over 26,400 participants, the seroprevalence was found to be only $0.73 \%$ (54). The lower rates of seroprevalence of SARS-CoV-2 antibodies reported from various geographical locations point in the direction that we are still a long way ahead of achieving herd immunity.

According to a modeling study, assuming a scenario of achieving uniform herd immunity threshold of $67 \%$ and with an infection fatality rate of $0.6 \%$ for SARS-CoV-2, the estimate of the absolute number of deaths worldwide would easily exceed a whopping 30 million (14). Since these estimates are based on various assumptions and the real-life scenario could throw us curve balls of multiple factors influencing the outcomes, the fatality rate could even be higher. A recent modelling study has estimated that about one in five individuals worldwide would be at increased risk of severe COVID-19, upon infection with SARS$\mathrm{CoV}-2$, owing to the underlying conditions. The study projects an alarming figure of about 349 million people requiring hospital admission and substantial mortality rates (55). 


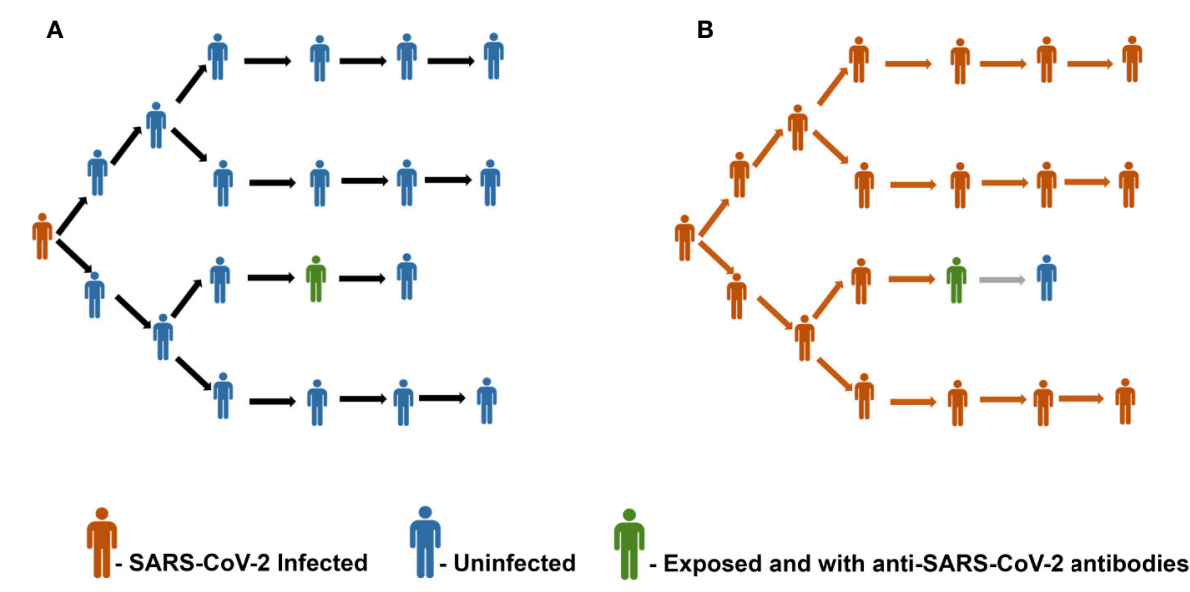

FIGURE 1 | (A) Representative image of a scenario with a population having 5\% seroprevalence of antibodies against SARS-CoV-2. Panel (B) depicts the unchecked spread of infection due to the insufficient herd immunity.

Furthermore, in the case of highly populated and resourcestrapped countries, the increase in the number of infected cases could overwhelm the healthcare facilities and could lead to a shortage of essential medical services exacerbating further complications and deaths.

\section{CONCLUSIONS}

Thus, weighing on the immunological and epidemiological consequences, achieving natural herd immunity at the cost of severe morbidities and mortalities worldwide, in the absence of an effective and safe vaccine appears farfetched and seemingly an impracticable solution. With so many vaccines being tested in various phases of clinical trials, the availability of an effective vaccine seems to be the only way forward in this war against COVID-19. Echoing Dr. Anthony Fauci's statements, even when a vaccine with a modest efficacy is made available in near future, anti-science and anti-vaccine campaigns need to be counteracted and cooperation of the general public is needed to achieve an efficient and successful herd immunity against COVID-19 (56).

\section{REFERENCES}

1. Dong E, Du H, Gardner L. An interactive web-based dashboard to track COVID-19 in real time. Lancet Infect Dis (2020) 20(5):533-4. doi: 10.1016/ S1473-3099(20)30120-1

2. Huang C, Wang Y, Li X, Ren L, Zhao J, Hu Y, et al. Clinical features of patients infected with 2019 novel coronavirus in Wuhan, China. Lancet (2020) 395 (10223):497-506. doi: 10.1016/S0140-6736(20)30183-5

3. WHO. Coronavirus Disease (COVID-19) Dashboard. Available at: https://covid19. who.int/?gclid=CjwKCAjw_qb3BRAVEiwAvwq6Vvsmd-BECU3AK qLye88rCMZf-MuZkHt9FJ70phH5wL5hb3fcqZsmhRoCVOIQAvD_BwE (Accessed September 01, 2020).

4. Topley WW, Wilson GS. The Spread of Bacterial Infection. The Problem of Herd-Immunity. J Hyg (Lond) (1923) 21(3):243-9. doi: 10.1017/S00221724 00031478

\section{AUTHOR CONTRIBUTIONS}

RV, ES, VV, and ST led the writing of this opinion article. All authors contributed to the article and approved the submitted version.

\section{FUNDING}

VV was supported by Emory University CFAR grant P30 AI050409 and NCRR/NIH base grants P30 RR00165, P51OD011132 (to Y.N.P.R.C.).

\section{ACKNOWLEDGMENTS}

The views, opinions, assumptions, or any other information set out in this article are solely those of the authors and should not be attributed to anyone. The authors salute all the health care workers who are at the front lines of the COVID-19 pandemic, helping patients and their families.

5. Fine PE. Herd immunity: history, theory, practice. Epidemiol Rev (1993) 15 (2):265-302. doi: 10.1093/oxfordjournals.epirev.a036121

6. Fine P, Eames K, Heymann DL. "Herd immunity": a rough guide. Clin Infect Dis Off Publ Infect Dis Soc Am (2011) 52(7):911-6. doi: 10.1093/cid/ cir007

7. Rashid H, Khandaker G, Booy R. Vaccination and herd immunity: what more do we know? Curr Opin Infect Dis (2012) 25(3):243-9. doi: 10.1097/ QCO.0b013e328352f727

8. Clemente-Suárez VJ, Hormeño-Holgado A, Jiménez M, Benitez-Agudelo JC, Navarro-Jiménez E, Perez-Palencia N, et al. Dynamics of Population Immunity Due to the Herd Effect in the COVID-19 Pandemic. Vaccines (2020) 8(2):236. doi: 10.3390/vaccines 8020236

9. Fox JP, Elveback L, Scott W, Gatewood L, Ackerman E. Herd immunity: basic concept and relevance to public health immunization practices. Am J Epidemiol (1971) 94(3):179-89. doi: 10.1093/oxfordjournals.aje.a121310 
10. Singhal T. A Review of Coronavirus Disease-2019 (COVID-19). Indian J Pediatr (2020) 87(4):281-6. doi: 10.1007/s12098-020-03263-6

11. Peng X, Xu X, Li Y, Cheng L, Zhou X, Ren B, et al. Transmission routes of 2019-nCoV and controls in dental practice. Int J Oral Sci (2020) 12(1):9. doi: 10.1038/s41368-020-0075-9

12. Zhou G, Zhao Q. Perspectives on therapeutic neutralizing antibodies against the Novel Coronavirus SARS-CoV-2. Int J Biol Sci (2020) 16(10):1718-23. doi: 10.7150/ijbs. 45123

13. Li Q, Guan X, Wu P, Wang X, Zhou L, Tong Y, et al. Early Transmission Dynamics in Wuhan, China, of Novel Coronavirus-Infected Pneumonia. $N$ Engl J Med (2020) 382(13):1199-207. doi: 10.1056/NEJMoa2001316

14. Randolph HE, Barreiro LB. Herd Immunity: Understanding COVID-19. Immunity (2020) 52(5):737-41. doi: 10.1016/j.immuni.2020.04.012

15. Sanche S, Lin YT, Xu C, Romero-Severson E, Hengartner N, Ke R, et al. High Contagiousness and Rapid Spread of Severe Acute Respiratory Syndrome Coronavirus 2. Emerg Infect Dis (2020) 26(7):1470-7. doi: 10.3201/eid2607.200282

16. Britton T, Ball F, Trapman P. A mathematical model reveals the influence of population heterogeneity on herd immunity to SARS-CoV-2. Science (2020) 369(6505):846-9. doi: 10.1126/science.abc6810

17. Aguas R, Corder RM, King JG, Goncalves G, Ferreira MU, Gomes MG. Herd immunity thresholds for SARS-CoV-2 estimated from unfolding epidemics. medRxiv (2020) 2020.07.23.20160762. doi: 10.1101/2020.07.23.20160762

18. Al-Tawfiq JA, Rodriguez-Morales AJ. Super-spreading events and contribution to transmission of MERS, SARS, and COVID-19. J Hospit Infect (2020) 105(2):111-2. doi: 10.1016/j.jhin.2020.04.002

19. Frieden TR, Lee CT. Identifying and interrupting superspreading eventsimplications for control of severe acute respiratory syndrome coronavirus 2. Emerg Infect Dis (2020) 26(6):1059-66. doi: 10.3201/eid2606.200495

20. Beldomenico PM. Do superspreaders generate new superspreaders? a hypothesis to explain the propagation pattern of COVID-19. Int J Infect Dis (2020) 96:461-3. doi: 10.1016/j.ijid.2020.05.025

21. Szapudi I. Heterogeneity in SIR epidemics modeling: superspreaders. medRxiv (2020) 2020.07.02.20145490. doi: 10.1101/2020.07.02.20145490.

22. Mo H, Zeng G, Ren X, Li H, Ke C, Tan Y, et al. Longitudinal profile of antibodies against SARS-coronavirus in SARS patients and their clinical significance. Respirol Carlton Vic (2006) 11(1):49-53. doi: 10.1111/j.1440-1843. 2006.00783.x

23. Payne DC, Iblan I, Rha B, Alqasrawi S, Haddadin A, Al Nsour M, et al. Persistence of Antibodies against Middle East Respiratory Syndrome Coronavirus. Emerg Infect Dis (2016) 22(10):1824-6. doi: 10.3201/eid2210. 160706

24. Okba NMA, Müller MA, Li W, Wang C, GeurtsvanKessel CH, Corman VM, et al. Severe Acute Respiratory Syndrome Coronavirus 2-Specific Antibody Responses in Coronavirus Disease 2019 Patients. Emerg Infect Dis (2020) 26 (7):1478-88. doi: 10.3201/eid2607.200841

25. Long Q-X, Liu BZ, Deng HJ, Wu GC, Deng K, Chen YK, et al. Antibody responses to SARS-CoV-2 in patients with COVID-19. Nat Med (2020) 26 (6):845-8. doi: 10.1038/s41591-020-0897-1

26. Grifoni A, Weiskopf D, Ramirez SI, Mateus J, Dan JM, Moderbacher CR, et al. Targets of $\mathrm{T}$ cell responses to SARS-CoV-2 coronavirus in humans with COVID-19 disease and unexposed individuals. Cell (2020) 181(7):1489501.e15. doi: 10.1016/j.cell.2020.05.015

27. Sette A, Crotty S. Pre-existing immunity to SARS-CoV-2: the knowns and unknowns. Nat Rev Immunol (2020) 7:1-2. doi: 10.1038/s41577-020-00430-w

28. Mateus J, Grifoni A, Tarke A, Sidney J, Ramirez SI, Dan JM, et al. Selective and cross-reactive SARS-CoV-2 T cell epitopes in unexposed humans. Science (2020) eabd3871. doi: 10.1126/science.abd3871

29. Ng K, Faulkner N, Cornish G, Rosa A, Earl C, Wrobel A, et al. Pre-existing and de novo humoral immunity to SARS-CoV-2 in humans. bioRxiv (2020) 2020.05.14.095414. doi: 10.1101/2020.05.14.095414

30. Kuri-Cervantes L, Pampena MB, Meng W, Rosenfeld AM, Ittner CA, Weisman AR, et al. Immunologic perturbations in severe COVID-19/SARSCoV-2 infection. bioRxiv (2020) 2020.05.18.101717. doi: 10.1101/2020.05. 18.101717

31. Thevarajan I, Nguyen THO, Koutsakos M, Druce J, Caly L, van de Sandt CE, et al. Breadth of concomitant immune responses prior to patient recovery: a case report of non-severe COVID-19. Nat Med (2020) 26(4):453-5. doi: $10.1038 /$ s41591-020-0819-2
32. Rodriguez L, Pekkarinen PT, Lakshmikanth T, Tan Z, Consiglio CR, Pou C, et al. Systems-level immunomonitoring from acute to recovery phase of severe COVID-19. Cell Rep Med (2020) 1(5):100078. doi: 10.1016/j.xcrm.2020. 100078

33. Liu J, Li S, Liu J, Liang B, Wang X, Wang H, et al. Longitudinal characteristics of lymphocyte responses and cytokine profiles in the peripheral blood of SARS-CoV-2 infected patients. EBioMedicine (2020) 55:102763. doi: 10.1016/ j.ebiom.2020.102763

34. Mathew D, Giles JR, Baxter AE, Oldridge DA, Greenplate AR, Wu JE, et al. Deep immune profiling of COVID-19 patients reveals distinct immunotypes with therapeutic implications. Science (2020), eabc8511. doi: 10.1126/science. abc8511

35. Odak I, Barros-Martins J, Bošnjak B, Stahl K, David S, Wiesner O, et al. Reappearance of effector T cells is associated with recovery from COVID-19. EBioMedicine (2020) 57:102885. doi: 10.1016/j.ebiom.2020.102885

36. Le Bert N, Tan AT, Kunasegaran K, Tham CYL, Hafezi M, Chia A, et al. SARS-CoV-2-specific T cell immunity in cases of COVID-19 and SARS, and uninfected controls. Nature (2020) 584(7821):457-62. doi: 10.1038/s41586020-2550-z

37. Juno JA, Tan HX, Lee WS, Reynaldi A, Kelly HG, Wragg K, et al. Humoral and circulating follicular helper $\mathrm{T}$ cell responses in recovered patients with COVID-19. Nat Med (2020) 26(9):1-7. doi: 10.1038/s41591-020-0995-0

38. Wu F, Wang A, Liu M, Wang Q, Chen J, Xia S, et al. Neutralizing antibody responses to SARS-CoV-2 in a COVID-19 recovered patient cohort and their implications. medRxiv (2020) 2020.03.30.20047365. doi: 10.1101/2020.03. 30.20047365

39. Suthar MS, Zimmerman MG, Kauffman RC, Mantus G, Linderman SL, Hudson WH, et al. Rapid generation of neutralizing antibody responses in COVID-19 patients. Cell Rep Med (2020) 1(3):100040. doi: 10.1016/j.xcrm. 2020.100040

40. Robbiani DF, Gaebler C, Muecksch F, Lorenzi JCC, Wang Z, Cho A, et al. Convergent antibody responses to SARS-CoV-2 in convalescent individuals. Nature (2020) 584(7821):437-42. doi: 10.1038/s41586-020-2456-9

41. Liu L, Wang P, Nair MS, Yu J, Rapp M, Wang Q, et al. Potent neutralizing antibodies against multiple epitopes on SARS-CoV-2 spike. Nature (2020) 584 (7821):450-6. doi: 10.1038/s41586-020-2571-7

42. Chen L, Xiong J, Bao L, Shi Y. Convalescent plasma as a potential therapy for COVID-19. Lancet Infect Dis (2020) 20(4):398-400. doi: 10.1016/S1473-3099 (20)30141-9

43. Li L, Zhang W, Hu Y, Tong X, Zheng S, Yang J, et al. Effect of Convalescent Plasma Therapy on Time to Clinical Improvement in Patients With Severe and Life-threatening COVID-19: A Randomized Clinical Trial]. JAMA (2020) 324(5):1-11. doi: 10.1001/jama.2020.10044

44. Callow KA, Parry HF, Sergeant M, Tyrrell DA. The time course of the immune response to experimental coronavirus infection of man. Epidemiol Infect (1990) 105(2):435-46. doi: 10.1017/S0950268800048019

45. Ibarrondo FJ, Fulcher JA, Goodman-Meza D, Elliott J, Hofmann C, Hausner MA, et al. Rapid decay of anti-SARS-CoV-2 antibodies in persons with mild Covid-19. N Engl J M (2020) 383(11):1085-7. doi: 10.1056/NEJMc2025179

46. Seow J, Graham C, Merrick B, Acors S, Steel KJ, Hemmings O, et al. Longitudinal evaluation and decline of antibody responses in SARS-CoV-2 infection. medRxiv (2020) 2020.07.09.20148429. doi: 10.1101/2020.07.09. 20148429.

47. To KK, Hung IF, Ip JD, Chu AW, Chan WM, Tam AR, et al. COVID-19 reinfection by a phylogenetically distinct SARS-coronavirus-2 strain confirmed by whole genome sequencing. Clin Infect Dis (2020) ciaa1275. doi: 10.1093/ $\mathrm{cid} / \mathrm{ciaa} 1275$

48. Chandrashekar A, Liu J, Martinot AJ, McMahan K, Mercado NB, Peter L, et al. SARS-CoV-2 infection protects against rechallenge in rhesus macaques. Science (2020) 369(6505):812-7. doi: 10.1126/science.abc4776

49. Syal K. COVID-19: herd immunity and convalescent plasma transfer therapy. J Med Virol (2020) 10.1002/jmv.25870. doi: 10.1002/jmv.25870

50. Pollán M, Pérez-Gómez B, Pastor-Barriuso R, Oteo J, Hernán MA, PérezOlmeda M, et al. Prevalence of SARS-CoV-2 in Spain (ENE-COVID): a nationwide, population-based seroepidemiological study. Lancet (2020) 396 (10250):535-44. doi: 10.2139/ssrn.3616010

51. Sood N, Simon P, Ebner P, Eichner D, Reynolds J, Bendavid E, et al. Seroprevalence of SARS-CoV-2-Specific Antibodies Among Adults in Los 
Angeles County, California, on April 10-11, 2020. JAMA (2020) 323 (23):2425-7. doi: 10.1001/jama.2020.8279

52. Doi A, Iwata K, Kuroda H, Hasuike T, Nasu S, Kanda A, et al. Estimation of seroprevalence of novel coronavirus disease (COVID-19) using preserved serum at an outpatient setting in Kobe, Japan: A cross-sectional study. medRxiv (2020) 2020.04.26.20079822. doi: 10.1101/2020.04.26.20079822

53. To KK, Cheng VC, Cai JP, Chan KH, Chen LL, Wong LH, et al. Seroprevalence of SARS-CoV-2 in Hong Kong and in residents evacuated from Hubei province, China: a multicohort study. Lancet Microbe (2020) 1(3): E111-8. doi: 10.1016/S2666-5247(20)30053-7

54. Murhekar MV, Bhatnagar T, Selvaraju S, Rade K, Saravanakumar V, Vivian Thangaraj JW, et al. Prevalence of SARS-CoV-2 infection in India: Findings from the national serosurvey, May-June 2020. Indian J Med Res (2020) 152(1 \& 2):48-60. doi: 10.4103/ijmr.IJMR_3290_20

55. Clark A, Jit M, Warren-Gash C, Guthrie B, Wang HHX, Mercer SW, et al. Global, regional, and national estimates of the population at increased risk of severe COVID-19 due to underlying health conditions in 2020: a modelling study. Lancet Global Health (2020) 8(8):e1003-17. doi: 10.1016/S2214-109X (20)30264-3

56. Correspondent EC CNN Senior Medical. Fauci says Covid-19 vaccine may not get US to herd immunity if too many people refuse to get it. CNN. Available at: https://www.cnn.com/2020/06/28/health/fauci-coronavirus-vaccine-contacttracing-aspen/index.html (Accessed June 30, 2020).

Conflict of Interest: The authors declare that the research was conducted in the absence of any commercial or financial relationships that could be construed as a potential conflict of interest.

Copyright $\odot 2020$ Vignesh, Shankar, Velu and Thyagarajan. This is an open-access article distributed under the terms of the Creative Commons Attribution License (CC BY). The use, distribution or reproduction in other forums is permitted, provided the original author(s) and the copyright owner(s) are credited and that the original publication in this journal is cited, in accordance with accepted academic practice. No use, distribution or reproduction is permitted which does not comply with these terms. 